\title{
The Measurement of Nephron Filtration Rate and Absolute Reabsorption in the Proximal Tubule of the Rabbit Kidney
}

\author{
Arnold M. Chonko, Richard W. Osgood, Allan E. Nickel, \\ Thomas F. Ferris, and Jay H. STein \\ From the Departments of Medicine, Ohio State University School of Medicine, \\ Columbus, Ohio, and the University of Texas Health Science Center, \\ San Antonio, Texas 78284
}

\begin{abstract}
A B S T R A C T Micropuncture studies were performed in the rabbit to determine nephron filtration rate and absolute fluid reabsorption in the proximal tubule in order to compare the latter value with data obtained with the in vitro microperfusion technique. New Zealand white rabbits, $2-2.8 \mathrm{~kg}$, were studied. Nephron filtration rate was $21 \mathrm{nl} / \mathrm{min}(n=48)$ and absolute reabsorption along the length of the accessible portion of the proximal convoluted tubule was $10.3 \mathrm{nl} / \mathrm{min}$. Correcting this value for tubular length gives a fluid reabsorption of approximately $1.9 \mathrm{nl} / \mathrm{mm}$ per min. In view of the marked difference between the in vivo and in vitro techniques and the various sources of error with each, this is reasonably similar to the value of $1.3 \mathrm{nl} / \mathrm{mm}$ per min obtained in the isolated proximal convoluted tubule.
\end{abstract}

\section{INTRODUCTION}

In 1966, Burg, Grantham, Abramow, and Orloff described a technique for preparation and study of single rabbit nephrons (1). In this study, it was found that isolated proximal tubules of the rabbit were able to maintain large transcellular concentration gradients for sodium, potassium, and chloride. The viability of

Received for publication 13 December 1974 and in revised form 2 April 1975. perfused proximal tubules was demonstrated by the presence of both active para-aminohippuric acid transport and net fluid absorption. Subsequent to this publication, the technique has been utilized to study a wide variety of questions concerning cellular transport in several segments of the nephron (2-9). Yet, little if any data is available to allow a comparison of the in vitro transport capacity of various nephron segments to the in vivo setting. This type of comparison would allow a more meaningful interpretation of the physiologic significance of the results obtained with the microperfusion technique. This report presents the first micropuncture data obtained in the rabbit kidney. The results indicate that the in vivo and in vitro measurements of absolute fluid absorption in the proximal tubule are reasonably similar.

\section{METHODS}

Studies were performed on male and female New Zealand white rabbits weighing between 2.0 and $2.8 \mathrm{~kg}$. The rabbits were anesthetized with pentobarbital $(30 \mathrm{mg} / \mathrm{kg})$ and subsequently given small maintenance doses as necessary. A polyethylene tube was inserted into the trachea and the animal was then allowed to breathe without a respirator. Polyethylene catheters were inserted into both jugular veins for infusion of inulin and injection of Lissamine green and in the femoral artery for blood pressure measurement and 
TABLE I

Summary of Rabbit Micropuncture Studies

\begin{tabular}{|c|c|c|c|c|}
\hline Exp. & $(\mathrm{TF} / \mathrm{P})_{\mathrm{In}_{\mathrm{n}}}$ & $\begin{array}{l}\text { Nephron } \\
\text { GFR }\end{array}$ & $\begin{array}{l}\text { Absolute } \\
\text { reabsorption }\end{array}$ & $\begin{array}{c}\text { Kidney } \\
\text { GFR }\end{array}$ \\
\hline & & $n l / \min$ & $n l / \min$ & $\mathrm{ml} / \mathrm{min}$ \\
\hline \multirow[t]{6}{*}{1} & $2.01^{*}$ & 12 & 6.0 & 4.01 \\
\hline & 1.44 & 20 & 5.7 & \\
\hline & 1.75 & 19 & 8.0 & \\
\hline & $1.92^{*}$ & 16 & 7.6 & \\
\hline & $1.88^{*}$ & 18 & 8.5 & \\
\hline & & $(17) \ddagger$ & & \\
\hline \multirow[t]{5}{*}{2} & 1.36 & 16 & 4.5 & 3.72 \\
\hline & 1.52 & 17 & 5.8 & \\
\hline & $1.81^{*}$ & 27 & 12.0 & \\
\hline & $2.02^{*}$ & 23 & 11.6 & \\
\hline & & $(21) \ddagger$ & & \\
\hline \multirow[t]{6}{*}{3} & 1.62 & 27 & 10.0 & 4.04 \\
\hline & $1.88^{*}$ & 18 & 8.4 & \\
\hline & $1.99^{*}$ & 27 & 13.5 & \\
\hline & $2.03^{*}$ & 25 & 12.3 & \\
\hline & $2.55^{*}$ & 16 & 9.8 & \\
\hline & & $(23) \ddagger$ & & \\
\hline \multirow[t]{6}{*}{4} & $2.01^{*}$ & 37 & 18.5 & 4.72 \\
\hline & 1.52 & 34 & 11.6 & \\
\hline & 1.72 & 30 & 12.6 & \\
\hline & $1.84^{*}$ & 31 & 14.6 & \\
\hline & $1.85^{*}$ & 33 & 15.2 & \\
\hline & & $(33) \ddagger$ & & \\
\hline \multirow[t]{3}{*}{5} & $1.93^{*}$ & 20 & 9.7 & 3.96 \\
\hline & $2.00^{*}$ & 24 & 12.0 & \\
\hline & 1.62 & $\begin{array}{l}17 \\
(20) \ddagger\end{array}$ & 6.6 & \\
\hline \multirow[t]{4}{*}{6} & 1.37 & 22 & 6.0 & 3.78 \\
\hline & $1.88^{*}$ & 19 & 8.9 & \\
\hline & 1.54 & 25 & 8.8 & \\
\hline & $2.03^{*}$ & $\begin{array}{l}18 \\
(21) \ddagger\end{array}$ & 9.1 & \\
\hline \multirow[t]{4}{*}{7} & 1.54 & 16 & 5.7 & 3.01 \\
\hline & 1.48 & 13 & 4.2 & \\
\hline & $1.94^{*}$ & 12 & 5.8 & \\
\hline & $1.88^{*}$ & $\begin{array}{c}12 \\
(13) \ddagger\end{array}$ & 5.6 & \\
\hline \multirow[t]{4}{*}{8} & $1.93^{*}$ & 22 & 10.7 & 3.52 \\
\hline & $1.97^{*}$ & 21 & 10.4 & \\
\hline & $1.94^{*}$ & 15 & 7.2 & \\
\hline & $2.25^{*}$ & $\begin{array}{c}18 \\
(19) \ddagger\end{array}$ & 10.0 & \\
\hline
\end{tabular}

* Late proximal tubular collection.

$\ddagger$ Mean nephron GFR per experiment.

blood collection. Both ureters were catheterized with PE 90 tubing through a suprapubic incision.

The left kidney was exposed through a small flank incision, the pedicle was gently dissected free, and the kidney was then placed in a Plexiglas cup. The capsule was left intact, and the surface of the kidney was bathed with mineral oil at $37^{\circ} \mathrm{C}$.

An infusion of inulin in Ringer's solution was given at a rate of $0.05 \mathrm{ml} / \mathrm{min}$ in order to establish and maintain an inulin concentration of approximately $100 \mathrm{mg} / 100 \mathrm{ml}$. Two to three $0.2-\mathrm{ml}$ intravenous injections of $10 \%$ Lissamine green were given to measure the transit time through the proximal tubule and to localize the last accessible segment on the surface of the rabbit kidney. At least 30 min elapsed between the last injection of Lissamine green and the collection of tubular fluid samples. Only rabbits with a proximal tubular transit time of $15 \mathrm{~s}$ or less that was uniform throughout the superficial cortex were utilized. These criteria were chosen because of previous experience with similar studies in the rat. 27 rabbits were prepared for micropuncture of which 15 met these criteria. The remaining 12 animals were not further studied. Approximately two-thirds of the collections were obtained from end proximal segments. $1 \mathrm{~h}$ after the inulin infusion had begun, three to five proximal tubular collections were obtained with sharpened pipettes with tip diameters varying from 7 to $10 \mu \mathrm{m}$. After puncture, a large column of mineral oil stained with Sudan black was injected into the tubule. After initial gentle aspiration to begin the collection, most of the samples were collected either spontaneously or with only occasional aspiration to maintain the oil column in a constant position. All tubular fluid collections were timed. Eight studies were performed in this manner. In six of these experiments transit times were repeated at the conclusion of all collections and were essentially unchanged. In three further studies, end proximal tubules were localized with Lissamine green, marked, injected with latex, and microdissected by the technique of Cortell (10) in order to measure the length

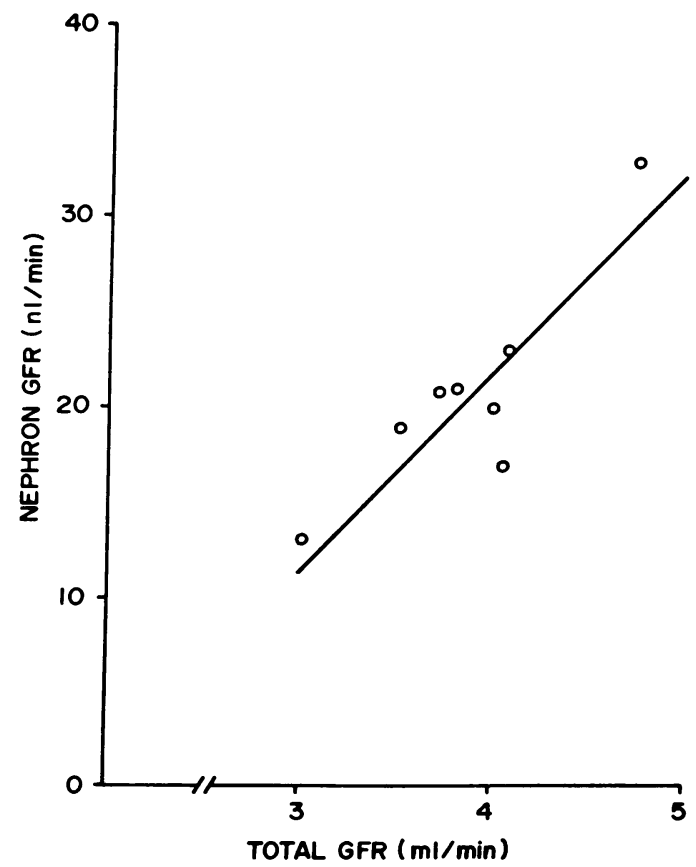

FIGURE 1 Relationship between nephron and total GFR. There was a linear relationship, $y=10.5 x-19.4(r=0.89$, $P<0.005)$. Each nephron GFR point is a mean of 3-5 measurements obtained from a single rabbit. $n=8$. 
of the accessible portion of the proximal convoluted tubule of the rabbit. In four additional studies, end proximal tubular collections were obtained followed by microdissection and length measurement of the punctured tubule.

In all studies, two 15-min clearance periods were collected from both kidneys. Plasma and urine inulin concentrations were determined by the anthrone method (11). The concentration of inulin in tubular fluid was measured by the fluorometric method of Vurek and Pegram (12). Tubular fluid volumes were measured in constant-bore quartz capillary tubes of a known internal diameter. Sodium and potassium concentrations in urine and plasma were measured by an Instrumentation Laboratory flame photometer (Instrumentation Laboratory, Inc., Watertown, Mass.).

Calculations. Nephron filtration rate $\left(\mathrm{V}_{0}\right)^{1}=(\mathrm{TF} / \mathrm{P})_{\text {In }}$ $\times V_{F}$, where $(T F / P)_{\text {In }}$ is the tubular fluid-to-plasma inulin ratio and $V_{F}$ is the tubular flow rate in nanoliters per minute. Absolute reabsorption of filtrate in proximal tubule in nanoliters per minute $=V_{0}-V_{F}$. The data were analyzed by standard statistical methods and all results are presented as the mean $\pm S E M$.

\section{RESULTS}

Total kidney glomerular filtration rate (GFR) in the micropuncture kidney averaged $3.84 \mathrm{ml} / \mathrm{min}$ (range $3.01-4.72 \mathrm{ml} / \mathrm{min}$ ). This value was slightly but consistently lower than in the untouched control kidney, which averaged $4.21 \mathrm{ml} / \mathrm{min}(P<0.05)$. In addition, urinary flow rate and sodium excretion were significantly lower in the micropuncture kidney. Urinary flow rate was 18 and $24 \mu \mathrm{l} / \mathrm{min}(P<0.02)$ while fractional sodium excretion was 0.32 and $0.42 \%(P<0.02)$ in the micropuncture and control kidney, respectively. Mean arterial pressure averaged $102 \pm 3 \mathrm{~mm} \mathrm{Hg}$ and was essentially constant throughout each study.

The results of the eight micropuncture studies are summarized in Table I. Vo was $21.1 \mathrm{nl} / \mathrm{min}$ for all 34 punctures and $20.9 \mathrm{nl} / \mathrm{min}$ when the mean of each of the eight experiments was averaged. In six of the eight studies, the mean nephron GFR ranged from 17 to $23 \mathrm{nl} / \mathrm{min}$ per study while in the remaining two experiments, the means were 33 and $13 \mathrm{nl} / \mathrm{min}$. Yet, in these two studies, the data were quite tight with a range of $30-37 \mathrm{nl} / \mathrm{min}$ in exp. 4 and $12-16 \mathrm{nl} / \mathrm{min}$ in exp. 7. The mean coefficient of variation of the nephron GFR measurement per experiment in these eight studies was $16 \%$, a value quite similar to previous results from this laboratory in the dog and rat $(13,14)$. Further evidence of the precision of these determinations is shown in Fig. 1, which compares total kidney and nephron GFR. A strong linear relationship was noted with an $r$ value of $0.89(P<0.005)$. In addition when the total GFR per gram kidney weight is divided by

\footnotetext{
${ }^{1}$ Abbreviations used in this paper: GFR, glomerular filtration rate; $(\mathrm{TF} / \mathrm{P})_{\mathrm{n}}$, tubular fluid-to-plasma inulin ratio; $V_{0}$, nephron filtration rate; $V_{F}$, tubular flow rate.
}

TABLE II

Direct Measurement of Absolute Fluid Reabsorption in Rabbit Proximal Tubule

\begin{tabular}{|c|c|c|c|c|}
\hline Exp. & $(\mathrm{TF} / \mathrm{P})_{\mathbf{I n}_{\mathbf{n}}}$ & $\begin{array}{l}\text { Nephron } \\
\text { GFR }\end{array}$ & $\begin{array}{l}\text { Tubular } \\
\text { length }\end{array}$ & $\begin{array}{l}\text { Absolute } \\
\text { reabsorption }\end{array}$ \\
\hline & & $n l / \min$ & $m m$ & $n l / m m / \min$ \\
\hline \multirow[t]{4}{*}{1} & 1.95 & 17 & 4.8 & 1.73 \\
\hline & 1.90 & 19 & 5.0 & 1.80 \\
\hline & 2.07 & 17 & 5.5 & 1.60 \\
\hline & 1.88 & 16 & 4.9 & $\begin{array}{l}1.53 \\
(1.66)^{*}\end{array}$ \\
\hline \multirow[t]{5}{*}{2} & 2.10 & 27 & 6.6 & 2.12 \\
\hline & 1.87 & 25 & 5.8 & 1.90 \\
\hline & 1.80 & 23 & 5.9 & 1.74 \\
\hline & 1.85 & 30 & 6.3 & 2.22 \\
\hline & & & & $(1.99)^{*}$ \\
\hline \multirow[t]{4}{*}{3} & 1.89 & 26 & 5.2 & 2.36 \\
\hline & 1.89 & 20 & 5.0 & 1.90 \\
\hline & 2.11 & 21 & 5.4 & 2.07 \\
\hline & & & & $(2.11)^{*}$ \\
\hline \multirow[t]{4}{*}{4} & 2.03 & 19 & 5.8 & 1.66 \\
\hline & 1.80 & 25 & 5.6 & 2.05 \\
\hline & 1.84 & 23 & 5.5 & 1.90 \\
\hline & & & & $(1.87)^{*}$ \\
\hline
\end{tabular}

* Mean absolute reabsorption of each experiment.

the nephron GFR, a mean value of 22,300 nephrons/g is obtained, which is quite close to the value of 23,000 nephrons/g kidney measured directly in the rabbit by Bankir, Farman, Grünfeld, de la Tour, and FunckBrentano (15).

22 of the 34 collections were obtained from end proximal segments. In these 22 collections, the mean (TF/ P) In, $V_{0}$, and absolute reabsorption were $1.97 \pm 0.03,21.1$ \pm 1.4 , and $10.3 \pm 0.07 \mathrm{nl} / \mathrm{min}$, respectively. Although not obtained in these studies, 12 measurements of the accessible length of the proximal tubule were done in three rabbits of the same size as in the studies in Table I. The mean value was $5.4 \pm 0.4 \mathrm{~mm}$. By utilizing this measurement and the absolute reabsorptive rate of 10.3 $\mathrm{nl} / \mathrm{min}$, a value of approximately $1.9 \mathrm{nl} / \mathrm{mm}$ per $\min$ is obtained.

Nephron GFR, absolute reabsorption, and tubular length were all determined in 14 end segments in four additional studies. As is shown in Table II mean absolute fluid absorption rates of 1.66, 1.99, 2.11, and $1.87 \mathrm{nl} / \mathrm{mm}$ per min were measured in these four experiments.

\section{DISCUSSION}

This study describes the first micropuncture data obtained in the rabbit kidney. As is shown in Table I, 
nephron GFR averaged approximately $20 \mathrm{nl} / \mathrm{min}$ and half of this amount was reabsorbed by the end of the accessible portion of the proximal tubule. The precision of the measurement of nephron GFR in the rabbit was adequate with a mean coefficient of variation of $16 \%$. In addition, the linear relationship between nephron and kidney GFR (Fig. 1) lends further credence to the nephron GFR measurement. Although the total kidney GFR was reduced $9 \%$ in comparison to the untouched contralateral kidney, this small difference would not seemingly have any major effect on the interpretation of these data.

By utilizing the data in Table I and the measured length of the accessible portion of the proximal tubule of $5.4 \mathrm{~mm}$, an absolute reabsorptive rate of approximately $1.9 \mathrm{nl} / \mathrm{mm}$ per min was obtained. In addition, in four further studies in which all parameters were measured in the same tubule, a similar value was obtained. In studies utilizing the in vitro microperfusion technique, this value has averaged approximately $1.3 \mathrm{nl} /$ $\mathrm{mm}$ per min in tubules from rabbits slightly smaller than those used in the present study $(2,4,5)$. In addition, Hamburger, Lawson, and Dennis have suggested that the proximal convolution is quite heterogeneous (16). Absorptive rates in the early part of the microperfused rabbit proximal tubule were closer to the values obtained in vivo averaging $1.6 \mathrm{nl} / \mathrm{mm}$ per min, while in late proximal tubules water movement was approximately $0.5 \mathrm{nl} / \mathrm{mm}$ per min, a value quite similar to that found in the straight portion of the proximal tubule.

Yet, even with these aspects taken into consideration, the in vivo and in vitro results are surprisingly similar in view of the marked differences in the two procedures and the various sources of error with each. Even if the presence of a capillary circulation, some constituent in the filtrate, or other factors do cause the absorptive rate in the proximal tubule to be higher in vivo, the values obtained with the in vitro perfusion technique are reasonably comparable.

\section{ACKNOWLEDGMENTS}

This work was supported in part by National Institutes of Health grants 5 TO1 HL05975-02S1, 5 RO1 AM13424-06, 2 RO1 HL13653-04, and PO1 AM17387 and by grants from the Central Ohio and American Heart Association.

\section{REFERENCES}

1. Burg, M., J. Grantham, M. Abramow, and J. Orloff. 1966. Preparation and study of fragments of single rabbit nephrons. Am. J. Physiol. 210: 1293-1298.

2. Burg, M. B., and J. Orloff. 1968. Control of fluid absorption in the renal proximal tubule. J. Clin. Invest. 47 : 2016-2024.

3. Kokko, J. 1970. Sodium chloride and water transport in the descending limb of Henle. J. Clin. Invest. 49: $1838-1846$

4. Horster, M., M. Burg, D. Potts, and J. Orloff. 1973. Fluid absorption by proximal tubules in the absence of a colloid osmotic gradient. Kidney Int. 4: 6-11.

5. Imai, M., and J. P. Kokko. 1972. Effect of peritubular protein concentration on reabsorption of sodium and water in isolated perfused proximal tubules. J. Clin. Invest. 51: 314-325.

6. Imai, M., and J. P. Kokko. 1974. Sodium chloride, urea, and water transport in the thin ascending limb of Henle. J. Clin. Invest. 53: 393-402.

7. Burg, M. B., and N. Green. 1973. Function of the thick ascending limb of Henle's loop. Am. J. Physiol. 224: 659-668.

8. Rocha, A. S., and J. P. Kokko. 1973. Sodium chloride and water transport in the medullary thick ascending limb of Henle. J. Clin. Invest. 52: 612-623.

9. Grantham, J. J., M. B. Burg, and J. Orloff. 1970. The nature of transtubular $\mathrm{Na}$ and $\mathrm{K}$ transport in isolated rabbit renal collecting tubules. J. Clin. Invest. 49: 18151826.

10. Cortell, S. 1969. Silicone rubber for renal tubular injection. J. Appl. Physiol. 26: 158-159.

11. Fuhr, J., J. Kaczarczyk, and C-D. Krüttgen. 1955. Eine einfache colormetrische Methode zur Inulinbestimmung für Nieren-Clearance-Untersuchungen bei Stoffwechselgesunden und Diabetikern. Klin. Wochenschr. 33: 729730.

12. Vurek, G. G., and G. E. Pegram. 1966. Fluorometric method for the determination of nanogram quantities of inulin. Anal. Biochem. 16: 409-419.

13. Stein, J. H., R. C. Congbalay, D. L. Karsh, R. W. Osgood, and T. F. Ferris. 1972. The effect of bradykinin on proximal tubular sodium reabsorption in the dog: evidence for functional nephron heterogeneity. J. Clin. Invest. 51 : 1709-1721.

14. Stein, J. H., R. W. Osgood, S. Boonjarern, and T. F. Ferris. 1973. A comparison of the segmental analysis of sodium reabsorption during Ringer's and hyperoncotic albumin infusion in the rat. J. Clin. Invest. 52: 2313-2323.

15. Bankir, L., N. Farman, J. P. Grünfeld, E. H. de la Tour, and J. L. Funck-Brentano. 1973. Radioactive microsphere distribution and single glomerular blood flow in the normal rabbit kidney. Pfluegers Arch. Eur. J. Physiol. 342: 111-123.

16. Hamburger, R. J., N. L. Lawson, and V. W. Dennis. 1974. Effects of cyclic adenosine nucleotides on fluid absorption by different segments of proximal tubule. Am. J. Physiol. 227: 396-401. 